$$
\begin{gathered}
\text { 무선 인지 셀룰러 망에서 자원예측에 의한 가드채널 } \\
\text { 할당기법의 성능개선 }
\end{gathered}
$$

\title{
Performance Improvements in Guard Channel Scheme by Resource Prediction for Wireless Cognitive Radio-Based Cellular Networks
}

\author{
이진이 ${ }^{*}$ \\ Jin-Yi Lee* \\ 요 약
}

본 논문에서는 셀룰러 기반 무선 인지망에서 핸드오프 호를 위한 가드채널할당기법(guard channel scheme)의 자원이용률의 저하를 개선하기 위해 무선인지 기술을 사용하여 자원 이용률을 향상시키면서, 무 선 인지망의 부 사용자(cognitive radio user) 손실률을 줄이는 방법을 제안한다. 제안한 방법에서는 핸드오 프 호의 전용채널(guard channel)을 부 사용자가 이용하도록 하고, MMOSPRED(Multi-Media One Step Prediction)기법으로 핸드오프 호의 발생을 예측한 다음, 핸드오프 호가 발생하면 핸드오프 호의 전용채널을 넘겨주고, 부 사용자는 예약된 자원으로 스펙트럼 핸드오프를 하여 서비스를 완료 하도록 한다. 시뮬레이션 을 통하여, 제안한 기법의 자원 이용률과 부 사용자의 손실률에 대한 성능이 기존의 가드채널 할당기법과 모바일의 이동성을 예측하지 않은 채널할당기법 보다 우수함을 보인다.

\section{Abstract}

In this paper, we propose a scheme for improving not only the utilization of frequency bands in the guard channel scheme but also the dropping rate of cognitive radio user in the wireless cognitive radio-based cellular network. The proposed scheme enables cognitive radio users to utilize the guard channel for servicing only handoff calls in normal times, but cognitive radio users must vacate the frequency channel when handoff call appearing. At this time our scheme ensures their seamless services for cognitive radio users, by predicting handoff call's appearance by MMOSPRED (Multi-Media One Step Prediction) method and then reserving the demanded channels for spectrum handoff calls. Our simulations show that our scheme performs better than other schemes; GCS(Guard Channel Scheme) and a scheme without prediction in terms of cognitive users call's dropping rate and resource utilization efficiency.

Keywords : Wireless cognitive radio-based cellular network, Cognitive radio user's call dropping rate, Resource utilization efficiency, Spectrum handoff call, MMOSPRED resource prediction.

오늘날 무선통신에서 서비스의 급격한 증가는 주

I. 서 론 파수 대역의 부족을 초래하고, 이를 해결하기 위한

* 청운대학교 전자공학과(Dept.of Electronics Engineering, Chungwoon University)

· 제1저자 (First Author) : 이진이

· 투고일자 : 2012년 8월 21일

· 심사(수정)일자 : 2012년 8월 23일 (수정일자 : 2012년 10월 27일)

· 게재일자 : 2012년 10월 30일 
기술로 무선인지기술이 소개되어 많은 연구가 진행 되고 있다[1],[2],[3]. 무선인지기술은 사용하지 않는 주파수 대역을 찾아내고, 그 주파수 대역을 이용할 수 있도록 통신 파라메타(주파수, 전력, 전송률 등)를 동적으로 조절하여 통신이 이루어지도록 한다. 이 기 술은 무선 주파수대역의 사용정도를 감지하고 사용 하지 않은 빈 주파수대역(spectrum hole)을 부 사용자 (unlicensed use, cognitive radio user)가 동적으로 스펙 트럼을 엑세스 할 수 있는 기술로서, 무선통신의 제 한된 주파수대역을 낭비 없이 효율적으로 이용할 수 있게 한다. 그리고 주 사용자(licensed user)는 주파수 대역을 우선적으로 사용할 수 있기 때문에 주 사용자 가 나타날 때는 언제든지 부 사용자는 사용하던 주 파수 대역을 비워주거나 전송전력을 감소시켜 주사 용자에게 간섭이 없도록 해야 한다. 이를 위해 부 사 용자가 주 사용자의 출현을 감지하는 기술이 연구되 고 있지만, 주 사용자에게 미치는 간섭을 완전히 피 할 수는 없다[4],[5].

또 다른 문제는 주 사용자가 나타나 부 사용자가 사용하던 스펙트럼을 비워주고 다른 대역으로 홉핑 (hopping)할 때, 일시적으로 부 사용자의 연결이 끊길 수도 있고, 때에 따라서는 부 사용자가 자주 대역을 비워 주어야 하는 경우도 있을 수 있다. 이러한 것은 결국 주 사용자에게는 간섭, 부 사용자에게는 스위칭 시간을 요구하게 되어 통신의 성능을 떨어뜨리게 된 다. 이와 관련한 연구로서 무선인지 시스템에서 부 사용자의 홉핑률(hopping rate) 과 주 사용자에 대한 간섭을 줄이고 최적의 자원할당을 위해, 트래픽 패턴 의 예측방법이 이용되고 있다. 이 트래픽 예측방법에 는 이전에 발생된 트래픽 특성을 기초로 예측하는 방 법[6],[7]과 트래픽 패턴의 모델링에 의한 예측방법이 있다[8][9].

한편 본 논문의 연구와 관련한 셀룰러 가반 이동 통신망에는 핸드오프호의 지속적인 서비스를 지원하 기 위한 여러 가지 채널할당 방법들이 있다[10],[11]. 이들 중 가드채널 할당방법은 핸드오프호가 전용으 로 사용하게 하는 채널할당방법으로 핸드오프 호가 예상보다 적게 발생하면 자원을 낭비하게 된다. 트래 픽 발생 상황에 따라 핸드오프 호의 전용채널의 크기 를 조정하는 동적 채널 할당방법은 채널의 이용률을
높일 수 있으나, 최적의 자원할당을 위해서는 셀 전 체의 트래픽 변동에 대한 정확한 정보가 필요하기 때 문에 큰 오버헤드 트래픽이 발생한다. 이러한 문제들 을 해결하기 위한 방법으로 핸드오프 호의 트래픽 패 턴 예측에 의한 예약기법이 제안되어 있다[12].

본 논문에서는 셀룰러 기반 이동 통신망의 핸드오 프 호를 지원하기 위한 가드채널 할당방법에서 무선 인지 기술을 사용하여 채널 사용률을 높이고, 부 사 용자의 스펙트럼 홉핑에 따른 손실률을 줄이는 방법 을 제안한다. 제안된 방법에서는 주 사용자인 핸드오 프 호의 가드채널을 기회적으로 부 사용자가 사용하 고, 핸드오프 호의 발생을 MMOSPRED 기법[7],[12] 으로 예측하여 가드 채널을 사용하고 있던 부 사용자 가 스펙트럼 핸드오프할 경우에는 예약된 채널을 사 용하게 함으로써 가드채널의 사용률을 높이고 부 사 용자의 서비스 완료율을 높인다. 2 장에서는 핸드오 프 호의 발생을 예측하는 MMOSPRED 기법에 대해 기술하고, 3 장에서는 셀룰러 기반 이동 통신망에서 의 가드채널 할당 방법과 본 연구의 인지 무선기술에 의한 채널 할당방법에 대해 기술한다. 4 장에서는 기 존의 채널 할당방법과 제안된 채널할당방법의 성능 을 자원이용률과 부 사용자의 손실률에서 비교하여 제안한 방법이 기존의 가드채널기법과 예측이 없는 채널할당기법보다 인지 사용자 호의 손실률과 자원 이용률에서 우수함을 보인다. 5 장에서는 본 논문의 결론을 제시하고, 향후 연구방향에 대해 기술한다.

\section{MMOSPRED 자원예측}

MMOSPRED 자원예측방법은 홈 셀과 이웃 셀에 서 핸드오프 호가 이전에 사용한 자원의 양과 이웃 셀로 부터 홈 셀로 모바일의 이동으로 인해 서비스 중인 호가 핸드오프 할 확률을 기초로, 앞으로 홈 셀 에서 핸드오프 호가 요구하는 자원의 양을 예측할 수 있다.

핸드오프 호 손실확률을 $C D P$ (calldropping probability) 이하가 되도록 홈 셀 $i$ 에 예약해야 할 최소 채널의 수 $N_{i}$ 는 (1) 식으로 주어진다. 


$$
N_{i} \geq m_{i}(t+\Delta t)+c(C D P) v_{i}(t+\Delta t)
$$

여기서, $C D P$ 는 목표 핸드오프호 손실확률, $c(C D P)$ 는 목표 핸드오프호 손실률을 만족시키는 표준 정규분포의 랜덤변수이다. $m_{i}$ 와 $v_{i}$ 는 각각 사 용한 채널수의 평균과 분산값을 나타내며, 식(2) 와 식(3)으로 표시된다.

$$
\begin{aligned}
& m_{i}(t+\Delta t)=f_{i}(t) p_{s}(\Delta t)+\frac{1}{r}\left\{p_{m}(\Delta t) \sum_{s=1}^{r} f_{s}(t)\right\} \\
& v_{i}(t+\Delta t)=\sqrt{f_{i}(t) v_{s}(\Delta t)+v_{m}(\Delta t) \sum_{s=1}^{r} f_{s}(t)}
\end{aligned}
$$

여기서, $f_{i}(t)$ 와 $f_{s}(t)$ 는 각각 홈 셀에서 핸드오 프 호가 사용하는 채널수 와 $r=6$ 개의 이웃 셀 중 하나의 셀 $s$ 에서 사용하는 채널수를 나타낸다. $p_{m}(\Delta t)$ 는 $\Delta t$ 초 후에 모바일 사용자가 이웃 셀로 이동할 확률값이다. $p_{s}(\Delta t)$ 는 $\Delta t$ 초 동안 현재의 셀에 머물 확률값으로 $1-p_{m}(\Delta t)$ 의 값을 갖는다.

분산값인 $v_{m}(\Delta t)$ 와 $v_{s}(\Delta t)$ 는 각각 식(4)과 식 (5) 로 주어진다.

$$
\begin{gathered}
v_{m}(\Delta t)=\frac{p_{m}(\Delta t)}{r}\left\{1-\frac{p_{m}(\Delta t)}{r}\right\} \\
v_{s}(\Delta t)=p_{s}(\Delta t)\left\{1-p_{s}(\Delta t)\right\}
\end{gathered}
$$

모바일이 현재의 셀에서 계속 서비스 할 확률값과 호의 채널 점유시간 $X_{D}$ 는 식 (6) 으로 표시된다.

$$
p_{s}(\Delta t)=P\left(X_{D}>\Delta t\right)=\exp \left(-\frac{\Delta t}{T_{\text {channel }}}\right)
$$

여기서, $T_{\text {channel }}$ 은 호의 평균 채널 점유시간을 나타낸다.

\section{III. 부 사용자 예약 채널할당}

핸드오프 호를 위해 전용채널을 할당하는 가드채 널 할당기법(Guard channel scheme)과 무선 인지기술 및 자원예약에 의한 부 사용자의 스펙트럼 할당기법 을 사용하여 기존의 가드채널 할당기법의 성능을 향 상시킨 채널할당기법을 기술한다.

\section{3-1 가드채널할당기법}

기지국의 전체 채널을 초기 발생 호가 사용하는 채널(normal channel) 과 핸드오프 호가 사용하는 전 용채널(guard channel)로 구분한다. 이 기법은 예상보 다 적은 핸드오프 호의 발생으로 인해 가드채널에 여 유용량이 있는 경우에도 초기 발생 호가 연결되지 못 하는 경우가 있어 자원의 이용률이 크게 떨어질 수 있다. 따라서 가드채널의 크기를 정할 때 네트워크 상에서 초기 발생 호 와 핸드오프 호 발생률에 대한 정확한 정보가 필요하다.

\section{3-2 제안한 부 사용자 예약 채널할당기법}

예약에 의한 부 사용자 채널할당 기법은 무선인지 기술에 의해 가드채널을 부 사용자들이 사용하다가 핸드오프 호가 발생할 때, 부 사용자는 가드채널을 넘겨주고 예약된 채널로 스펙트럼 핸드오프를 하게 하여 서비스를 계속 할 수 있게 한다. 이 방법은 무선 인지 기술을 사용하여 주 사용자에 해당하는 핸드오 프 호가 사용할 자원을 부 사용자들이 사용하게 함으 로써 스펙트럼 이용률을 향상시킬 수 있고, 핸드오프 호의 발생을 예측하고, 부 사용자를 위한 채널을 예 약함으로써 부 사용자가 서비스 중에 종료되는 손실 률을 줄일 수 있다. 그림 1 은 셀의 전체용량을 셀룰 러 망의 발생 호(초기 발생 호, 핸드오프 호) 와 무선 인지기술에 의한 스펙트럼 핸드오프 호(부 사용자 호) 가 공유하는 채널을 나타낸 것이다. 


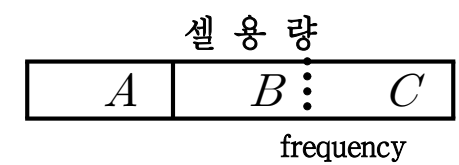

그림 1. 셀 용량 분배

Fig.1 Resource management in the proposed scheme.

셀의 전체 대역폭 중 $A$ 대역폭은 핸드오프 호와 무선 인지망의 부 사용자 호가 사용하는 주파수 대역 이고, 대역폭 $B$ 는 핸드오프 호 인 주 사용자가 출현 할 때 부 사용자가 스펙트럼 핸드오프를 하여 서비스 를 계속할 수 있도록 하기 위해 예약된 주파수 대역 이다. 대역폭 $C$ 는 셀룰러 망에서의 초기 발생 호가 사용하는 주파수 대역이다. 여기에서는 제 3 의 서비 스를 고려하여 셀룰러 망의 초기 발생 호와 무선 인 지망의 부 사용자 호를 구분하였다.

\section{IV. 성능평가}

무선인지기술과 핸드오프 호 발생예측 및 부 사용 자 채널예약기법을 사용하는 채널할당기법(CASE 1), 자원 이용률을 높이기 위해 무선인지 기술에 의하여 부 사용자가 핸드오프 호가 사용하지 않은 가드채널 을 일시적으로 사용하지만, 주 사용자에 해당하는 핸 드오프 호의 발생을 예측하지 않는 채널할당기법 (CASE 2), 그리고 기존의 GCS 채널할당기법에 대해 자원의 이용률과 부 사용자의 손실률을 평가 비교한 다.

무선인지 셀룰러망은 6 개의 이웃 셀을 갖는 6 각 형 망 구조 이고, 호의 평균 지속시간은 $200[\mathrm{sec}]$ 인 지 수함수분포, 호의 평균채널 점유시간은 $100[\mathrm{sec}]$ 인 지수함수분포를 각각 갖는 것으로 한다. 모든 호의 도착은 포아송 분포(평균 도착률 $\lambda$ )를 한다. MMOSPRED 예측 방법에서 정해주는 핸드오프 호의 목표 손실률은 5[\%], 셀의 채널용량은 $200[\mathrm{BUs}]$ 로 정 하고, 그 중 70[BUs]는 가드채널로 사용한다. 핸드오 프 호와 초기 발생 호는 호 당 $1[\mathrm{BU}]$ 의 채널을 사용 한다.

무선 인지망에서 주 사용자와 부 사용자의 일반적 인 주파수 대역 구조는 그림 2 과 같다[13]. 주 사용
자가 사용하는 $M$ 개의 기본 대역(primary bands)과 각각의 기본대역을 $N$ 개의 부 대역(cognitive radio bands)으로 나누어 각각의 부 대역을 부 사용자가 사 용한다. 즉, 같은 주파수대역을 overlap 하여 사용하 고 있으며, 주 사용자는 스펙트럼 사용에 우선권을 갖고 있고, 부 사용자가 기회적으로 사용하는 부 대 역을 다시 요구할 수 있도록 되어 있다. 또한, 주 사 용자는 부 사용자가 자신의 스펙트럼을 사용하고 있 다는 사실을 알고 있다.본 논문에서는 주 사용자인 핸드오프 호의 서비스를 위한 기본대역을 $N=6$ [개]의 부 대역으로 나누어 부 사용자가 사용하는 것 으로 한다.

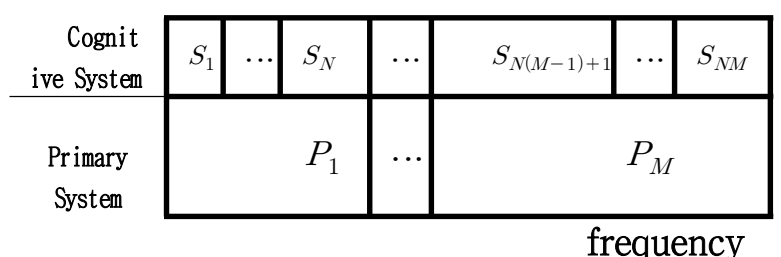

그림 2. 무선 인지망에서 주 사용자와 부 사용자의 주파수 대역

Fig. 2 Frequency bands used by cognitive radio user and primary user.

\section{4-1 MMOSPRED 예측성능}

MMOSPRED 예측기법을 사용하여 핸드오프 호가 요구하는 자원의 양(채널 수)을 예측한 것을 그림 3 에 나타낸다. 핸드오프 호의 평균 도착률 $\lambda_{h}=0.2$ [개/초], 예측간격은 1 [sec] 로 하고, $c(C D P)$ 는 $C D P \leq 0.5$ 을 만족하는 값을 선택한다. 핸드오프 호가 요구하는 예측된 자원의 양은 실제 요 구하는 자원의 양보다 평균적으로 $1[\mathrm{ch}]$ 이하의 예 측 오차값을 갖는다.

\section{4-2 자원 이용률}

그림 4 는 CASE 1, CASE 2, 기존의 GCS 채널할당 기법에 대해 셀 자원 전체에 대한 자원 이용률을 비 교한 것이다. 


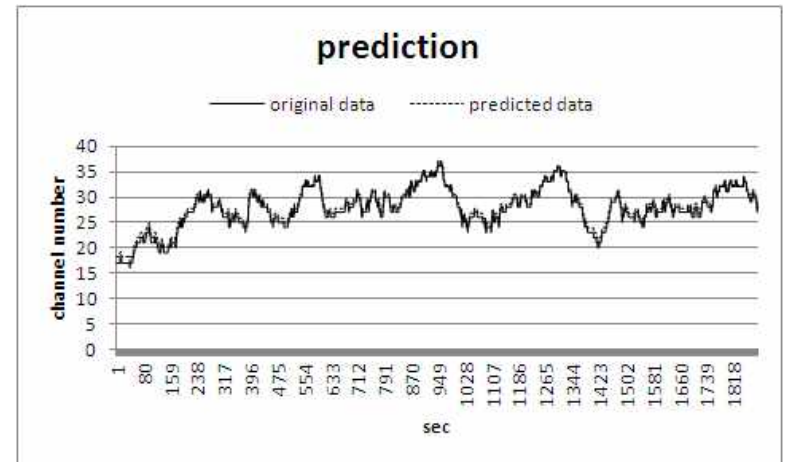

그림 3. 핸드오프 호가 요구하는 실제 자원의 양과 예측된 자원의 양

Fig.3. The number of channels requested by handoff calls : actual versus prediction.

$\left(\lambda_{h}=0.2[\right.$ 개/초], $\Delta t=1[\mathrm{sec}], C D P \leq 0.5)$

핸드오프 호 발생률 $\lambda_{h}=0.2$ [개/초] 와 초기 발 생 호의 도착률 $\lambda_{n}=0.2$ [개/초] 일 때, 부 사용자의 발생률 $\lambda_{C R}=0.6 \sim 3.0$ [개/초]에 따른 자원이용률 을 나타낸 것이다. $\lambda_{C R}=0$ 는 무선 인지기술을 사 용하지 않을 경우를 나타내며, 기존의 GCS 채널할당 기법에 해당한다.

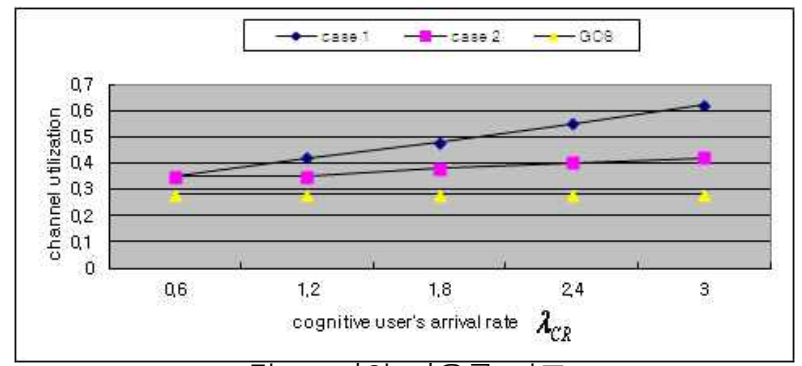

그림 4. 자원 이용률 비교

Fig. 4. Comparison of resource utilization $\operatorname{efficiency}\left(\lambda_{h}=0.2\right.$ [개/초], $\lambda_{n}=0.2$ [개/초])

CASE 1 인 경우에는 CASE 2의 경우보다 자원 이 용률이 높다. 즉, CASE 1 과 CASE 2 의 경우, $\lambda_{C R}$ 이 작을 경우에는 스펙트럼 핸드오프 하는 경우의 수 가 상대적으로 적기 때문에 자원이용률에서 큰 차이 가 없으나, $\lambda_{C R}$ 이 증가할수록 자원이용률에서 현저 한 차이를 볼 수 있다. 이것은 CASE 1 인 경우는 $\lambda_{C R}$ 이 증가할수록 부 사용자가 스펙트럼 핸드오프 하여 여유채널을 예약하여 사용하는 경우가 증가하 기 때문이다.

그러나 CASE 2 는 여유채널이 있을 때도 부 사용
자를 위한 채널을 예약하지 않기 때문에 상대적으로 자원 이용률이 낮다. 이것은 $\lambda_{C R}$ 이 증가하더라도 부 사용자가 사용할 수 있는 채널은 핸드오프 호 전 용채널 $(A)$ 로 제한되어 있기 때문이다. CASE 1 경우 가 평균적으로 $10[\%]$ 이상의 자원이용률 증가를 보 였다.

\section{4-3 부 사용자의 스펙트럼 핸드오프 호의 손실률}

셀룰러 기반 무선인지 망에서 주 사용자인 핸드오 프 호의 발생을 예측하고, 부 사용자가 스펙트럼 핸 드오프를 해야 할 경우에는 예약된 채널로 핸드오프 하여 지속적인 서비스를 유지하도록 한다. 이때 셀룰 러 망의 초기 호의 발생률이 증가하여 예약할 수 있 는 여유채널이 없을 때는 큐잉을 이용하는 방법이 있 으나 본 논문에서는 손실되는 것으로 한다.

그림 5 는 핸드오프 호 발생률 $\lambda_{h}=0.2$ [개/초], 초기 발생 호의 도착률 $\lambda_{n}=0.2$ [개/초] 이고 부 사 용자 호의 발생률 $\lambda_{C R}=0.6 \sim 3.0$ [개/초] 일때, CASE 1, CASE 2 기법에 대해, 부 사용자 호가 서비 스 중 핸드오프 호가 출현하였을 때 스펙트럼 핸드오 프를 하지 못하고 손실되는 경우를 비교한 것이다.

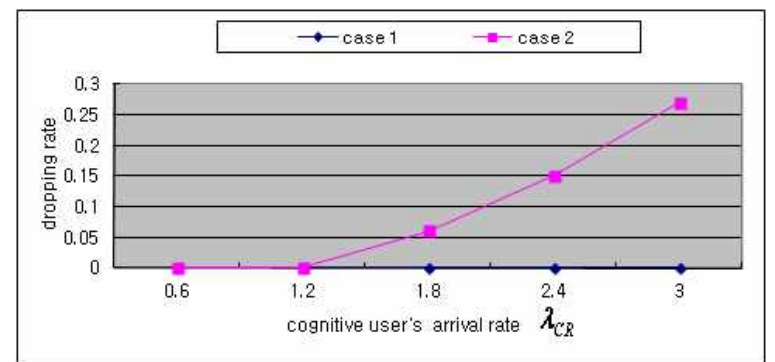

그림 5. 부 사용자 호의 손실률 비교

Fig. 5. Comparison of call dropping rate in cognitive radio user.

$$
\left(\lambda_{h}=0.2 \text { [개/초], } \lambda_{n}=0.2 \text { [개/초] }\right)
$$

CASE 1 에서 부 사용자 호가 손실되는 경우는 $C$ 주파수 대역을 먼저 초기 발생 호가 사용하고, 남은 채널이 없어 부 사용자를 위한 채널을 예약할 수 없 을 때이다. 그림 5 에서는 스펙트럼 핸드오프가 필요 한 부 사용자를 모두 예약할 수 있어 손실이 없음을 보인다. CASE 2 의 경우 $\lambda_{C R}$ 이 증가할수록 인지 사 
용자는 주 사용자의 출현으로 인해 기회적으로 사용 하던 가드채널에서 스펙트럼 핸드오프하는 경우의 수가 증가하지만 채널을 예약하여 서비스를 지속하 지 않기 때문에 호 손실이 증가하게 된다. CASE 2 경 우 인지 사용자의 호 손실률이 평균 9.6[\%] 를 보이 는 반면에 CASE 1 인 경우는 0 [\%]를 보인다. 따라서 시뮬레이션을 통하여 CASE 1 은 무선인지 기술에 의 해 핸드오프호의 전용채널중 사용하고 있지 않은 채 널을 인지한 후, 부 사용자가 그 채널을 사용할 수 있 게 하고, 핸드오프 호가 다시 출현할 것을 대비해 MMOSPRED 예측기법으로 출현 시기와 채널요구량 을 예측하여, 예약해 둠으로써 자원이용률을 높이고 부 사용자가 서비스 중에 손실되는 경우를 방지할 수 있음을 알 수 있다.

\section{V. 결 론}

한정된 무선 대역폭 자원을 효율적으로 이용하기 위한 무선 인지망 기술은 기회적 스펙트럼 엑세스를 통하여 통신이 이루어지기 때문에, 사용자의 서비스 품질을 만족시키는 것이 해결해야 하는 문제 중 하나 이다. 본 논문에서는 셀룰러 기반 무선 인지 망에서 무선인지 기술을 사용하여 가드채널 할당기법의 자 원 활용률을 높이고, 인지 사용자의 지속적인 서비스 를 보장하기 위해, 주 사용자(핸드오프 호)의 출현을 예측하고 인지 사용자의 동적 스펙트럼 핸드오프에 필요한 자원을 예약하는 기법을 제안하였다. 성능평 가를 통하여 제안한 기법이 $\lambda_{C R}$ 이 증가할수록 상대 적으로 자원이용률이 크게 증가하고, 인지 사용자의 호 손실률이 거의 없음을 보였다. 향후 연구는 분산 무선 인지망에서 호 수락 제어와 간섭경감을 위해 예 측기법을 이용하는 것이다.

\section{감사의 글}

본 연구는 2012년도 청운대학교 학술연구조성비 지원에 의하여 연구되었음

\section{참 고 문 헌}

[1] J. Mitola III, "Cognitive radio: an integrated agent architecture for software defined radio," Dissertation, Doctor of Technology, KTH Royal Institute of Technology, Sweden, May 2000.

[2] J. Mitola III and G. Q. Maguire Jr., "Cognitive radio: making software radios more personal," IEEE Presonal Comm., vol. 6, no. 4, pp.13-18, Aug. 1999.

[3] I. F. Akyildiz, W.-Y. Lee, et al., "NeXt generation / dynamic spectrum access / cognitive radio wireless networks : a survey," Computer Networks, vol. 50, pp.2127-2159, 2006.

[4] D. Cabric, S. M. Mishra, and R. W. Brodersen," Implementation issues in spectrum sensing for cognitive radios," Conference Record of the Thirty Eighth Asilomar Conference on signals, Systems and Computers, vol. 1, pp. 772-776, Nov. 2004.

[5] B. Wild and K. Ramchandran, " Detecting primary receivers for cognitive radio application," Proc. IEEE DySPAN 2005, pp. 124-130, Nov, 2005.

[6] S. Haykin, " Cognitive radio brain-empowered wireless communications," IEEE J. Select. Areas Comm., vol. 23, pp. 201-220, Feb. 2005.

[7] Tao Zhang, Eric van den Berg, Jasmine Chennikara, Prathima Agrawal, Jyh-Cheng Chen, and Toshikazu Kodama, "Local Predictive Resource Reservation for Handoff in Multimedia Wireless IP Networks," IEEE J. Select. Areas Commun., vol.19, no.10, Oct. 2001.

[8] P. Moungn, et al., "GSM Traffic forecast by combining forecasting technique," Information, Communications and Signal Processing, pp. 429-433, Dec. 2005.

[9] F. Kohandam, et al., "Wireless airtime traffic estimation using a state space model," Proc. CNSR, pp. 8, May 2006.

[10] M. H. Chiu and M. A. Bassiouni, "Predictive scheme for handoff prioritization in cellular networks based on mobile positioning," IEEE J. Select. Areas Commun., vol. 18, Mar. 2000.

[11] N. E. Rikli, "Effect of Terminal Mobility on Prioritized Handover of Multimedia Traffic over Cellular Wireless Networks," WCNC 2007 Proceedings, pp. 3656-3660. 
[12] 이진이,“ MMOSPRED 무선자원 예측방법을 이용 한 무선망의 이동성예측 자원할당” 한국정보기술 학회 논문집, vol. 5, no. 3, pp. 107-112, 2007.

[13] W. Ahemed, et al.," Comments on "Analysis of Cognitive Radio Spectrum Access with Optimal Channel Reservation,"

" IEEE Trans. on Wireless Commun., vol. 8, no.9, Sept. 2009.

이 진 이(李鎭伊)

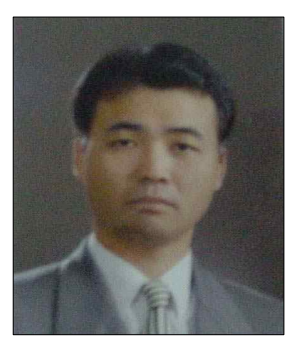

1985년 숭실대학교 전자공학과 학사. 1988년 숭실대학교 전자공학과 석사. 1994년 숭실대학교 전자공학과 박사. 1986년 7월 현재 : IEEE ComSoc member. 2011년 1월 2012년 1월 방문교수, UBC, Canada.

1995년 3월 현재 청운대학교 전자 공학과 교수.

관심분야: Broad bandwidth wireless networks, Mobile System. 